\title{
DETECTION OF COMMON BETA THALASSEMIA MUTATIONS AMONG EGYPTIAN PATIENTS
}

\author{
Osama Shaalan $^{1}$, Ahmed Daif ${ }^{1 *}$, Khalil Elhalfawy ${ }^{2}$ \\ ${ }^{1}$ Molecular Diagnostics and Therapeutics Department, Genetic Engineering and \\ Biotechnology Research institute (GEBRI), University of Sadat City, Egypt \\ ${ }^{2}$ Molecular Biology Department, Genetic Engineering and Biotechnology \\ Research institute (GEBRI), University of Sadat City, Egypt
}

* To whom correspondence should be addressed: Molecular Diagnostics and Therapeutics Department, Genetic Engineering and Biotechnology Research institute (GEBRI), University of Sadat City, Egypt.

\begin{abstract}
Beta-thalassemia is one of most common autosomal recessive disorders worldwide. High prevalence is present in populations in the Mediterranean, Middle-East, Transcaucasia, Central Asia, Indian subcontinent, and Far East. It is also relatively common in populations of African descent. The highest incidences are reported in Cyprus, Sardinia, and South East Asia. In Egypt, although more than 20 different mutations have been detected so far to cause the disease, the information available concerning the underlying molecular defects in bthalassemia has not yet been completed. The current study aims to detect the most common $\beta$ -globin gene mutations in Egypt among $\beta$-thalassemic patients by using PCR based reverse hybridization method (StripAssay) for the most prevalent $22 \beta$-globin gene mutations in the mediterranean population in an attempt to estimate the incidence of each mutation, and an attempt to improve our control strategy of $\beta$ - thalassemia. This study included a total of 37 confirmed $\beta$ - thalassemia ethnic Egyptian patients ( 23 males and 14 females) out of them 17 patients were a thalassemia major and 20 were a thalassemia intermediate. Evaluation of $\beta$ thalassemia mutations revealed that, the presence of 9 different $\beta$-globin mutations. The most frequent mutation were IVS 1-110[34\%], IVS 1-6(23.5\%), IVS 1-1(19\%), Codon 27[6.5\%], IVS 2-848[6.5\%], IVS 2-745[2.1\%] and IVS 2.1 [2.5\%], Codon 39[4\%]), and IVS 1.5 [1.5\%]. IVS $1-110[\mathrm{G}>\mathrm{A}]$ is the commonest homozygous mutation while, IVS 1-110[G>A]/ IVS 1$6[\mathrm{~T}>\mathrm{C}]$ is the commonest heterozygous mutation. Three mutations (IVS 1-110[G>A], IVS 1$6[\mathrm{~T}>\mathrm{C}]$, IVS $1-1[\mathrm{G}>\mathrm{A}]$ ) were account for about $76 \%$ of mutations in our studded alleles. In conclusion, knowledge of these mutations can provide an insight into the prognosis for individual patients, especially in young ages or before birth to take proper measures in advance and eventually ameliorate the symptoms in the long run.
\end{abstract}

Keywords: $\beta$-Thalassemia, mutations, $\beta$-Globin Strip Assay (reverse dot-blot PCR), PCR. Article type: Research Article

\section{INTRODUCTION}

Thalassemia is a globin gene disorder that results in a diminished rate of synthesis of one or more of the globin chains and, consequently, a reduced rate of synthesis of the hemoglobin. Beta-thalassemia syndromes are a group of hereditary blood disorders characterized by reduced or absent beta globin chain synthesis (1). Betathalassemia is caused by the reduced (beta+) or absent (beta0) synthesis of the beta globin chains of the hemoglobin $(\mathrm{Hb})$ tetramer, which is made up of two alpha globin and two beta globin chains (alpha2beta2). Beta-thalassemia homozygotes may develop either thalassemia major or thalassemia intermedia. (2). The reduced amount $(B+)$ or absence (BO) of beta globin chains result in a relative excess of unbound alpha globin chains that precipitate in erythroid 
precursors in the bone marrow, leading to their premature death and hence to ineffective erythropoiesis. The degree of globin chain reduction is determined by the nature of the mutation at the beta globin gene located on chromosome (3). High prevalence is present in developing countries whereas the health problem is prominent and shortage of the healthcare delivery strategy. The highest incidences are reported in populations of African descent, Mediterranean, Middle-East, Transcaucasia, Central Asia, Indian and Cyprus (4). Therefore, a thalassemia prevention program in these countries is highly needed (5). The position of Egypt in the center of the Middle East and as in many Mediterranean countries, $\beta$ thalassemia in Egypt considered as a major

\section{SUBJECTS AND METHODS Subjects}

The study participants were among a group of attendants to the hematology clinic of Abulrish hospital, Cairo University, Egypt. They comprised males and females suffering from $\beta$-thalassemia disease. Diagnosis of $\beta$-thalassemia disease was based on history, clinical examination and hematological investigations. All investigations were done in accordance with the Cairo University, health and human Ethical Clearance Committee guidelines for clinical researches. After obtaining informed consent, all participants were questioned in regard to their personal and family medical histories.

\section{Methods}

All affected patients were clinically classified into thalassemia major and thalassemia intermediate by collecting their peripheral venous blood for complete hematological examination with consideration to; the age of disease onset, the age of first transfusion, frequency of blood transfusion, hepatosplenomegaly, facial and growth affection.

$\beta$-Globin stripassay public health problem (6). Due to the limited resources of Egypt, its healthcare system is unable to deal properly with such a large number of sick babies. Therefore, community based prevention system must be that includes identification of carrier patients, genetic counseling and prenatal diagnosis (7-9). More than 200 mutations are detected to cause $\beta$-thalassemia, the information available concerning the underlying molecular defects in $\beta$ thalassemia has not yet been completed. (10). $\beta$-thalassemia mutations varies significantly among different geographical areas, there for The success of carrier screening and prenatal diagnosis depends on the information of prevalent mutations of such area (11-15).

Reverse dot-blot PCR was done using $\beta$-Globin StripAssay MED ${ }^{\mathrm{TM}}$, (ViennaLab Diagnostics GmbH, Gaudenzdorfer Gurtel, Vienna, Austria). First, DNA was extracted from peripheral blood leukocytes obtained from EDTA anti coagulated blood samples according to standard protocols and commercial kits. The isolated DNA was subjected to multiplex PCR amplification reaction using biotinylated primers. The resulted amplified $\beta$-globin products are then selectively hybridized to a test strip containing wild type and mutant oligonucleotide probes immobilized as parallel lines. The color of the Bound biotinylated sequences is then developed. The assay covers 22 mutations, characteristics for the Mediterranean area.

\section{Statistical analysis}

Statistical Package for Social Sciences (SPSS) computer program (version 19 windows) was used for data analysis as follows: quantitative variables Results are expressed as mean \pm standard deviation (SD) or number (\%). While the qualitative variables as number and percentage. $\mathrm{P}$ value $\leq 0.05$ was considered significant and $<0.001$ was considered highly significant. 


\section{RESULTS AND DISCUSSION}

This study included a total of 37 ethnic Egyptian patients (23 males and 14 females) who were confirmed to have $\beta$ thalassemia. Out of the $\beta$-thalassemia, 17 patients were a thalassemia major and 20 were a thalassemia intermediate. Clinical data from the studded subjects are shown in Table 1.

Hematological data of study subjects revealed that, there were significantly lower

Evaluation of $\beta$-thalassemia mutations in 37 patients with 74 alleles revealed the presence of 9 different $\beta$ globin mutations. The most frequent mutation is IVS $1-110[\mathrm{G}>\mathrm{A}]$ which account for about $34 \%$ of the studied alleles followed by IVS 1-6(T-C) which represent about $23.5 \%$. While IVS 1-1(G-A) account hemoglobin $(\mathrm{Hb})$, and significantly higher reticulocytes, platelets and white blood cells (WBCs) in patients with thalassemia major compared with patients with thalassemia intermedia. Moreover there were no significant differences between patients with thalassemia major and thalassemia intermedia as regard mean corpuscular volume (MCV) and mean corpuscular hemoglobin $(\mathrm{MCH})$ as shown in Table 2.

for $19 \%$. Other less frequent mutations as Codon 27[G>T] and IVS 2-848[C>G] presented by $6.5 \%$ for each mutation, IVS $2-745[\mathrm{C}>\mathrm{G}]$ and IVS $2.1[\mathrm{G}>\mathrm{A}]$ presented by $2.5 \%$ for each mutation, Codon $39[\mathrm{C}>\mathrm{T}])$ account for $4 \%$ and IVS 1.5 [G>C] represented by $1.5 \%$ as shown in Fig. 1.

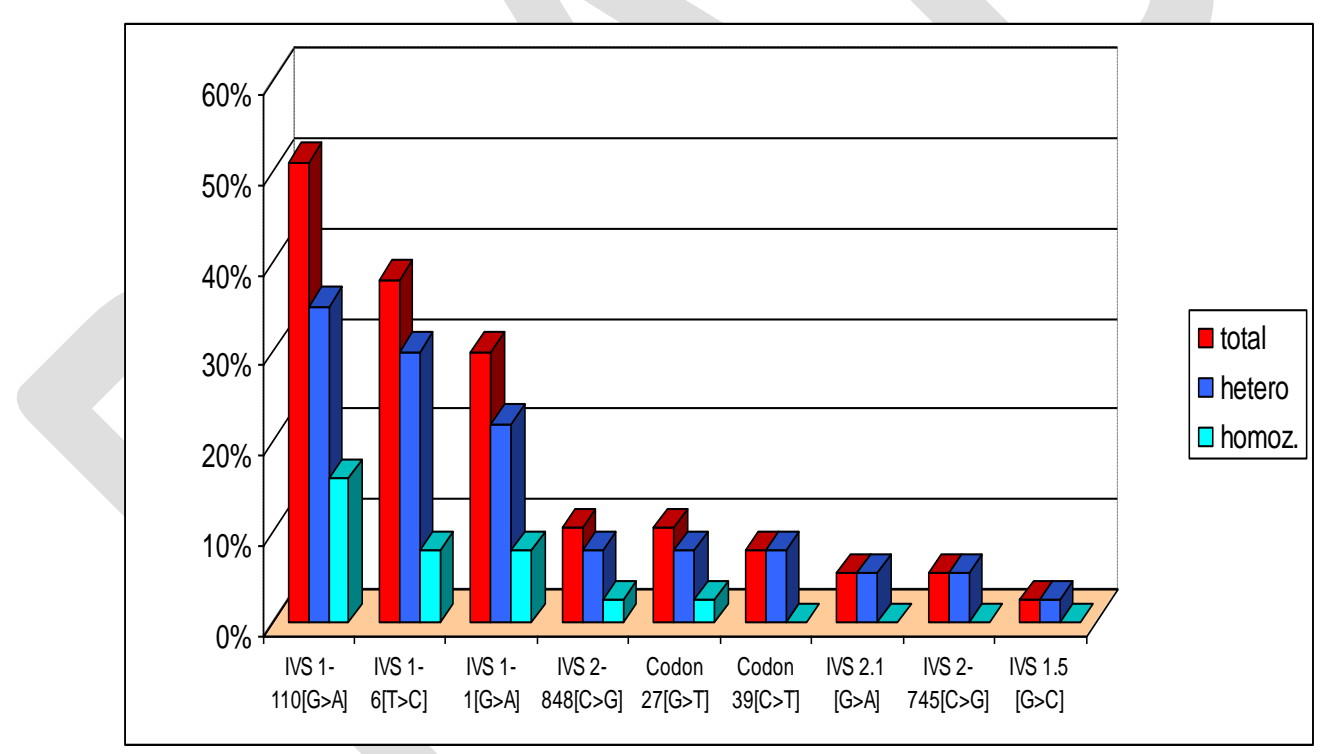

Fig 1. $\beta$-Globin gene mutations. Diagram describes the distribution and frequency of $\beta$ thalassemia mutations among carrier patients.

Three mutations (IVS $1-110[\mathrm{G}>\mathrm{A}]$, IVS $1-6[\mathrm{~T}>\mathrm{C}]$, IVS $1-1[\mathrm{G}>\mathrm{A}]$ ) were account for about $76 \%$ of mutations in our studded alleles. The other 6 less common mutations (IVS 2-848[C>G], Codon 27[G>T], IVS 2-745[C>G], IVS $2.1[\mathrm{G}>\mathrm{A}]$, Codon 39[C>T]), IVS $1.5 \quad[\mathrm{G}>\mathrm{C}]$ ) represented about 24\%. IVS 1-110[G>A] represents the most common homozygous mutations 6 out of 14 homozygous cases about $43 \%$. In compound heterozygous cases, IVS 1-110[G>A] also is the most common heterozygous mutation account for 13 out of 23 of our heterozygous cases representing about 56\%. Next IVS1-6 $[\mathrm{T}>\mathrm{C}]$ represents the second common homozygous mutations 3 out of 14 homozygous cases about $21 \%$. In compound heterozygous cases, IVS 1$6[\mathrm{~T}>\mathrm{C}]$ is the second common compound heterozygous mutation present in 11 out of 23 of our heterozygous cases account for $47 \%$. Followed by IVS $1-1[\mathrm{G}>\mathrm{A}]$ which represents the second common homozygous 
mutations 3 out of 14 homozygous cases about $21 \%$. In compound heterozygous cases, IVS 1-1[G>A] occupy the third place in compound heterozygous mutations account for 8 out of 23 of compound heterozygous cases representing about $34 \%$

Fig. 2.

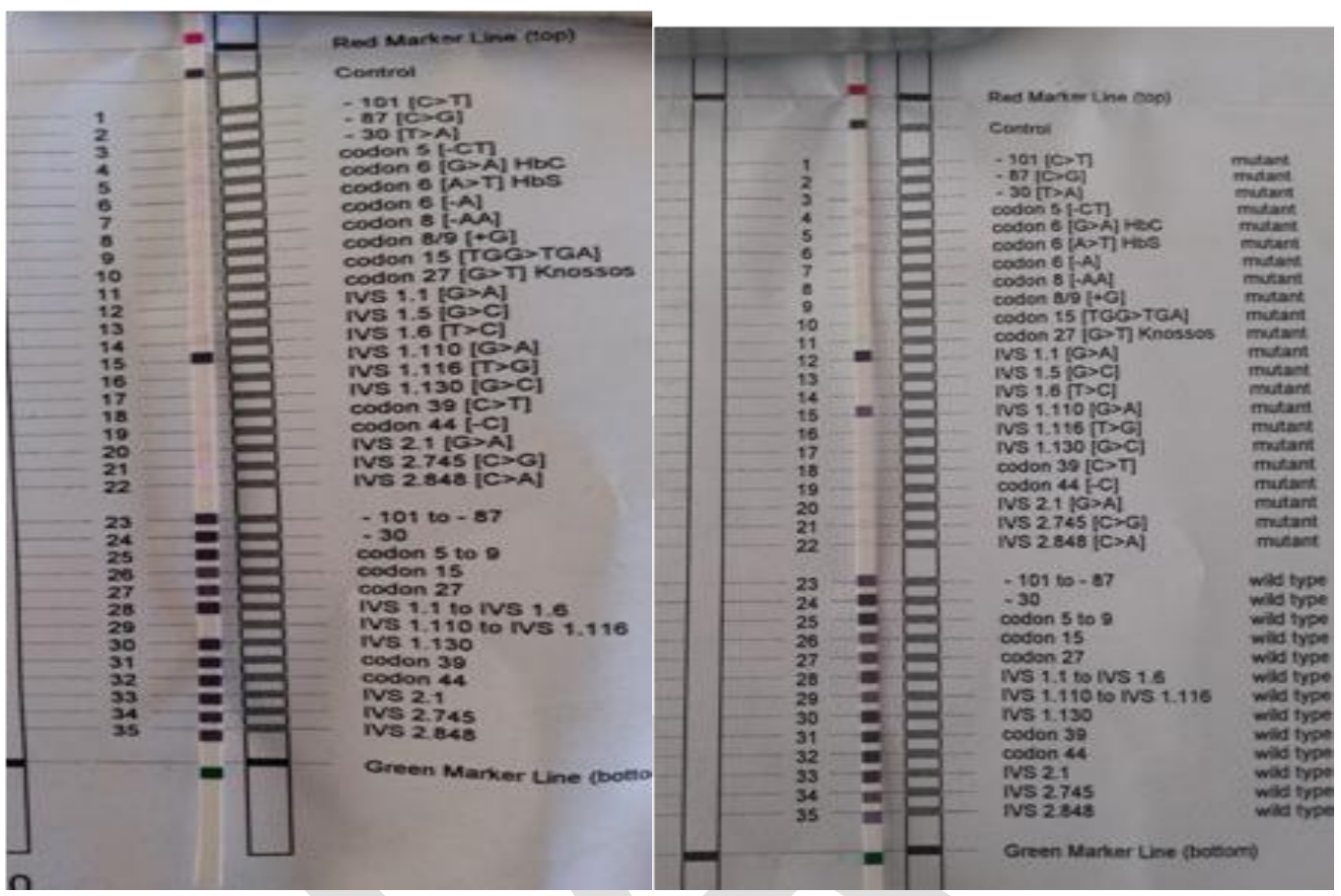

Fig 2.ß-Globin gene mutations Representative of the test strip used in the study (homozygous IVS $1-110[\mathrm{G}>\mathrm{A}]$ andIVS $1-110[\mathrm{G}>\mathrm{A}] / \mathrm{IVS} 1-1[\mathrm{G}>\mathrm{A}]$ compound heterozygous)

Beta Thalassemia is a group of hemoglobin diseases caused by a reduction $(b+)$ or abolish (b0) in the synthesis of $\beta$ globin chains. Carrier individuals can be either compound heterozygous, or homozygous for $\beta$-thalassemia [16].

$\beta$-Thalassemia is the most common genetically inherited $\beta$-globin disorder in Egypt.(17). Combined effects of high carrier rates and high frequency of consanguineous marriages make prevalence of $\beta$-thalassemia particularly high in Egypt (18).Up to date in Egypt, carrier detection and genetic counseling and carrier identification is essentially presented to families with an affected individual. In these families, the phenotypic and genotypic evaluation is usually performed in these families to determine the prognosis and to offer the comprehensive genetic counseling. For further reduce the incidence of new births of children with $\beta$-thalassemia (19).
Despite efforts to develop a therapy or bone marrow transplantation for $\beta$ thalassemia, still the prenatal diagnosis followed by termination of the affected fetus remains the best form of prevention. Until now, more than 200 different mutations have been described in patients with $\beta$-thalassemia. So the aim of this study is to find rapid, sensitive accurate method to detect the affected individuals, carrying the $\beta$-globin gene mutations and applicability of this method to use in prenatal diagnosis and further prevention of the disease.

In our studied, the commonest symptoms in the subjected patients were Pallor and jaundice while the most common signs werehepatomegaly and splenomegaly. This is in accordance with $(20,21)$.

In 37 patients with 74 alleles revealed the presence of 9 different $\beta$-globin mutations. The most frequent mutation is 
IVS 1-110[G>A] which account for about $34 \%$ of the studded alleles followed by IVS $1-6(\mathrm{~T}-\mathrm{C})$ which represent about $23.5 \%$. These results are in agreement with El Fadaly et al, 2015, Elmezayen et al., 2015 and El-Beshlawy et al, 2012, (18, 23-24).

IVS $1-110[\mathrm{G}>\mathrm{A}]$ is the commonest homozygous mutation found in 6 out of 14 homozygous cases accounting for about $43 \%$ of homozygous mutations. IVS 1$110[\mathrm{G}>\mathrm{A}] /$ IVS $1-6[\mathrm{~T}>\mathrm{C}]$ is the commonest heterozygous mutation found in 6 out of 23 heterozygous cases accounting for about $26 \%$ of heterozygous mutations. Our results are in agreement with the resultsof El-Beshlawy et al, 2012, and Jifri et al, 2010 (24-25). On the other hand

\section{REFERENCES}

Bain BJ. The alpha, beta, delta and gamma thalassaemias and related conditions. In Haemoglobinopathy Diagnosis, 2nd Edition. Wiley-Blackwell. Oxford; 2006:63-138.

Olivieri N, Weatherall DJ. Clinical aspects of -thalassemia. In: Steinberg $\mathrm{MH}$, Forget BG, Higgs DR, Nagel RL, editors. Disorders of hemoglobin, genetics, pathophysiology, and clinical management. Cambridge, University, 2001:277-341.

Galanello R, Origa R.Betathalassemia. Orphanet Journal of Rare Diseases 2010, 5:11. doi: 10.1186/17501172-5-11.

Weatherall DJ, Clegg JB, Higgs DR, Wood WG. The hemoglobinopathies. In:Scriver CR, Beaudet Al, Sly WS, Valle $\mathrm{D}$, Vogelstein B, editors. The metabolic and molecular bases of inherited disease (OMMBID). Chapter 101. New York, NY: McGraw-Hill, 2002. Available at: www.ommbid.com. AccessedDecember 31, 2007

Al-Allawi NA, Jubrael JM, Hughson M. Molecular characterization of beta
El -Gawhary et al., 2007 and Elmezayen et al., $2015(26,23)$ reported that IVSI-6 is more frequent than IVSI-110.

\section{CONCLUSION}

Knowledge of $\beta$-thalassemia mutations and their incidence may be a step in the heterogeneity detection of thalassemic carrier patients; consequently, prenatal diagnosis in families at-risk can reduce the incidence and the severity of the disease and thus can provide an insight into the prevention strategy for this disease.

\section{Declaration of Interest:}

The authors report no conflicts of interest thalassemia in the Dohuk region of Iraq. Hemoglobin 2006; 30:479-486.

El-Beshlawy A, Kaddah N, Ragab L, Hussein I, Mouktar G, Moustafa A, El Raouf E, Hassaballa N, Gaafarand T, ElSendiony $\mathrm{H}$. Thalassemic prevalence and status in Egypt. Proceedings of the annual meeting of the American Pediatric Society, San Francisco, CA, USA, (1-4 may 1999); abstract 102 .

Ahmed S, Saleem M, Modell B, Petrou M. Screening extended families for genetic hemoglobin disorders in Pakistan. N Engl J Med. 2002;347:1162-1168.

Ahmed S. Prenatal diagnosis of $\beta$ thalassemia: 12 years' experience at a single laboratory in Pakistan. Prenatal Diag. 2007;27:1224-1227.

Naseem S, Ahmed S, Vahidy F. Impediments to prenatal diagnosis of beta thalassemia: experiences from Pakistan. Prenatal Diag. 2008;28:1116-1118.

Omar A, Abdel Karim E, El Gendy W, Marzouk I, Wagdy M (2005) Molecular basis of beta thalassemia in Egypt. Egypt $\mathrm{J}$ Immunol 12(1):15-24.

Colah R, Gorakshakar A, Nadkarni A, et al. Regional heterogeneity of $\beta$ thalassemia mutations in the multi ethnic Indian population. Blood Cells Mol Dis. 2009;42(3):241-246.

Edison ES, Shaji RV, Devi SG, et al. Analysis of $\beta$ globin mutations in the Indian 
population: presence of rare and novel mutations and region-wise heterogeneity. Clin Genet. 2008;73(4):331-337.

Black ML, Sinha S, Agarwal S, et al. A descriptive profile of $\beta$-thalassemia mutations in India, Pakistan and Sri Lanka. J Commun Genet. 2010;1:149-157.

Başak AN. The molecular pathology of $\beta$-thalassemia in Turkey: The Boğazıçı University experience. Hemoglobin. 2007;31:233-241.

. Akhavan-Niaki H, DerakhshandehPeykar P, Banihashemi A, et al. A comprehensive molecular characterization of beta thalassemia in a highly heterogeneous population. Blood Cells Mol Dis. 2011;47:29-32.

Hussein G, Fawzy M, El-Serafi T et al (2007) Rapid detection of b-thalassemia alleles in Egypt using naturally or amplified created restriction sites and direct sequencing: a step in disease control. Hemoglobin 31(1):49.

- El-Beshlawy A and Youssry I. Prevention of hemoglobinopathies in Egypt. Hemoglobin 2009; 33 (1):14-20.

EL-Fadaly, A. Abd-Elhameed, E. Abd-Elbar, M. El-Shanshory. Accuracy of Reverse Dot-Blot PCR in Detection of Different b-Globin Gene Mutations. Indian J Hematol Blood Transfus 2015.

Barrai I, Vullo C. Assessment of prospective genetic counseling in the Ferrara area. Am J Med Genet 1980; 6(3):195-204.
Soliman HH, Kabbash IA, ElShanshory MR et al (2012) Evaluation of immune status against hepatitis $B$ in children with thalassemia major in Egypt. JMID 2:44-49.

Galanello R, Barella S, Satta S, Maccioni L, Pintor C, Cao A. Homozygosity for nondeletion delta-beta( 0 ) thalassemia resulting in a silent clinical phenotype. Blood 2002;100:1913-1914.

Cao A, Galanello R. Betathalassemia. Genet Med. 2010;12:61-76

El mezayen A. Kotb S, Ahmed M, et al. (2015): $\beta$-globin mutations in egyptian patients with $\beta$-thalassemia. LabMed. 46:813.

El-Beshlawy, A. El-Shekha, M. Momtaz, F. Said, M. Hamdy, O. Osman, S. Meshaal, T. Gafaar and M. Petrou (2012): Prenatal diagnosis for thalassaemia in Egypt: what changed parents'attitude. Prenatal Diagnosis 32,1-6.

Jiffri E, Bogari $\mathrm{N}$, Zidan $\mathrm{K}$, et al.(2010): Molecular updating of $\beta$ thalassemia mutations in the upper Egyptian population. Hemoglobin, 34(6):538-547.

El-Gawhary S, El-Shafie S, Niazi M, et al. (2007): Study of $\beta$-thalassemia mutations using the polymerase chain reaction amplification refractory mutation system and direct DNA sequencing techniques in a group of Egyptian thalassemiapatients. Hemoglobin, 31: 6369. 